\title{
O MERCADO FLEXIBILIZADO E A PRECARIZAÇÁO DO TRABALHO DO CIBERTARIADO
}

\author{
THE FLEXIBLE MARKET AND THE PRECARIZATION OF \\ CYBERTARIUM'S WORK
}

\author{
Suzy Elizabeth Cavalcante Koury ${ }^{1}$ (i) \\ Alex Albuquerque Jorge Melém ${ }^{\text {II }}$ (b)
}

${ }^{\mathrm{I}}$ Centro Universitário do Pará, Belém, PA, Brasil. E-mail: suzykoury@gmail. com

${ }^{\text {II }}$ Centro Universitário do Pará, Belém, PA, Brasil. E-mail: alexmelem@hotmail. com

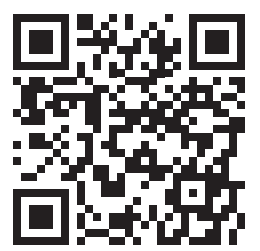

DOI: http://dx.doi.org/10.31512/rdj.v20i38.163

Recebido em: 08.08.2019

Aceito em: 29.06.2020
Resumo: $O$ presente estudo busca responder se a flexibilização do mercado provoca a precarização do trabalho, em especial quanto ao novo proletariado de serviço, também denominado de "cibertariado". Para tanto, utiliza-se do método dedutivo de pesquisa, por meio de revisão bibliográfica. A análise se inicia com a divisão social do trabalho, conforme avaliado por Marx (2013), e a sua nova configuração inserida com o mercado flexibilizado. Aborda-se o mercado analisando o Fordismo, a partir de Harvey (1989), como modelo de produçáo em larga escala, destacando-se os seus efeitos e características, assim como o surgimento do Toyotismo, como símbolo do sistema flexibilizado, que passa a caracterizar diversos segmentos econômicos, em especial por meio da terceirização. Foca-se, ainda, no novo proletariado de serviços, com base em Antunes (2014), que é utilizado para verificar o enquadramento dessa nova classe em um trabalho decente, em especial, quanto à remuneração e às justas condiçóes. Ao final, com base em Coutinho (2015), Barreto Júnior (2012), Silva (2002), Nascimento (2007), Araújo (2013), Takahashi (2014) e Almeida (2009), concluise que o mercado flexibilizado provoca um processo de precarizaçáo da "sociedade laboral", impactando-a, tanto pela perda de direitos e garantias trabalhistas, quanto pelo comprometimento da preservaçáo de seu bem mais precioso, a vida dos seus integrantes.

Palavras-chave: Terceirização. Trabalhadores de telemarketing. Trabalho decente. Precarização.

Abstract: The present study seeks to answer whether the flexibilization of the market causes the precariousness of work, especially regarding the new service proletariat, also called "cyber-work". For this, the deductive research method is used, through bibliographic review. The analysis begins with the social division of labor, as assessed by Marx (2013), and its new configuration inserted with the flexible market. The market is approached by analyzing Fordism, from Harvey (1989), as a model of large-scale production, highlighting its effects and characteristics, as well as the emergence of 


\begin{abstract}
Toyotism, as a symbol of the flexible system, which becomes characterize several economic segments, especially through outsourcing. It also focuses on the new service proletariat, based on Antunes (2014), which is used to check the fit of this new class in decent work, especially with remuneration and fair conditions. In the end, based on Coutinho (2015), Barreto Júnior (2012), Silva (2002), Nascimento (2007), Araújo (2013), Takahashi (2014) and Almeida (2009), it is concluded that the flexible market causes a process of precariousness in the "labor society", impacting it, both by the loss of labor rights and guarantees, as well as by the commitment to preserve its most precious asset, the lives of its members.
\end{abstract}

Keywords: Outsourcing, telemarketing workers. Decent labour. Precariousness.

\section{Consideraçóes iniciais}

A visão da sociedade de classes, proposta por Marx (2013), não é, atualmente, suficiente para descrever todas as relaçóes sociais e de labor, tendo em vista os efeitos que a flexibilização provocam na forma de administrar e de produzir as empresas. Essa nova maneira de atuar no mercado é caracterizada pela mercadorização, compreendida como a transformaçáo de atividades que eram inerentes às empresas em atividades de serviço, $o$ que é possibilitado por elementos de flexibilização, em especial, a terceirização.

O processo de mercadorização e flexibilização das classes trabalhadoras apresenta como principal resultado a ampliação dos contratos flexíveis (part time, temporário e afins) e da terceirização, que é o principal instrumento de apoio a tais políticas. Assim, o objetivo deste artigo, que utiliza o método dedutivo de pesquisa, efetuada pela revisáo bibliográfica de doutrinas pertinentes ao tema, tanto nacionais quanto estrangeiras, é analisar se os efeitos da flexibilização da relação de trabalho influenciam na sua precarizaçáo. Por conseguinte, os objetivos específicos são: avaliar a nova divisão do trabalho, sob a influência da flexibilização; abordar a terceirização, compreendendo o seu papel na sociedade, e, por fim, verificar se a relação de trabalho flexibilizada atende aos requisitos para o enquadramento como trabalho decente.

O texto está estruturado em três seções, excluindo as consideraçôes iniciais, as consideraçóes finais e as referências. Na seção 2, apresenta-se à divisão social do trabalho, como desenvolvida por Marx (2013) e a ascensão da nova classe proletária, o "cibertariado". Na seção 3, observa-se o desenvolvimento da nova classe proletária no mercado flexibilizado, destacando-se o papel da terceirização, como instrumento de flexibilização, e a sua importância para a estrutura em rede do mercado. Os efeitos desta nova divisão social do trabalho são analisados na seção 4, que destaca a precarização do 
labor e a inobservância dos requisitos para a caracterização de um trabalho decente no mercado terceirizado.

\section{A divisáo social do trabalho}

Ao longo da história humana observamos uma tendência à constantes modificaçóes na forma de estruturação da sociedade, provocada por suas diversas formas de organização, principalmente relacionadas as relaçóes laborais. Essa tendência à inovaçáo conduz ao próprio conceito de sociedade, que, segundo Castilho (2009, p. 1), pode ser descrita como "uma oportunidade, como algo por vir, uma tendência emergente ou que se impóe, como uma realidade consolidada”.

A fim de se observar um padrão mínimo de organização social, torna-se necessário destacar a visão de Marx (2013) acerca da divisão social do trabalho. Para Marx (2013, p. 529), essa divisão tem como origem as relaçóes tribais, caracterizadas por aspectos etários e de gêneros, apresentando um critério de diferenciação puramente fisiológico. Posteriormente, as tribos passaram a ter capacidade produtiva maior do que a necessária para o seu sustento, com o avanço das técnicas de produção na agricultura e com a domesticação dos animais, possibilitando o aparecimento de novas relaçóes sociais e comerciais, inclusive de dominação, representadas pelo surgimento das propriedades privadas, pela escravização dos prisioneiros de guerra e pela dissolução das relaçóes comunais (BARRADAS, 2014, p. 38).

A divisão social do trabalho, compreendida como a troca de mercadorias entre esferas de produçáo independentes e originalmente distintas entre si, apresenta como pressuposto básico a separação entre a cidade e o campo e a consequente relação sinalagmática entre ambos (MARX, 2013, p. 530). Essa divisão social do trabalho não se caracteriza por firmeza e imutabilidade, e sim por um caráter universal e dependente das diferentes formas e conteúdos sociais que se adquire, tendo como estrutura inicial sua íntima ligação com a organização social do trabalho e com a sua noção de planejamento (BARRADAS, 2014, p. 44).

Complementando essa relação, Marx (2013, p. 158) desenvolve a ideia de valor, relacionando-a à noção de utilidade, que está vinculada ao "corpo" da mercadoria negociada, as quais, em conjunto, formam o denominado "valor de uso da mercadoria", que independe do trabalho despendido, pois está ligado à quantidade de produto fornecido (MARX, 2013, p. 158). Essa ideia permite a troca de mercadorias em sociedades diversas, vez que torna menos importantes as características qualitativas do produto, sendo a quantidade de labor o seu ponto valorativo, o que facilita a permuta (MARX, 2013, p. 160). Dessa noção de valor, relacionada ao trabalho, extraímos os conceitos de trabalho simples e de trabalho complexo, que justificam a diferença valorativa entre práticas de 
trabalho humano. Deste modo, "o valor das mercadorias é determinado pela quantidade de trabalho nelas cristalizado" (BARRADAS, 2014, p. 51) ou, segundo Marx (2013, p. 169):

é dispêndio da força de trabalho simples que, em média, toda pessoa comum, sem
qualquer desenvolvimento especial, possui em seu organismo corpóreo. O próprio
trabalho simples médio varia, decerto, seu caráter em diferentes países e épocas culturais,
porém é sempre dado numa sociedade existente. O trabalho mais complexo vale apenas
como trabalho simples potenciado ou, antes, multiplicado, de modo que uma quantidade
menor de trabalho complexo é igual a uma quantidade maior de trabalho simples.

Essa noção é fundamental para se entender a própria lógica da divisão social do trabalho, que é relacionada à dinamização das relaçôes laborativas e ao desenvolvimento das diversas formas de "equivalência" da noção de valor e de sua potencialização (BARRADAS, 2014, p. 50), ou seja, a divisão social do trabalho apresenta sua organização adaptada à evoluçáo das relaçóes laborais e ao modo como essas relaçóes produzem as mercadorias, que seráo determinadas de acordo com os trabalhos simples e complexo despendidos para a sua confecção. Assim, a mercadoria agrega o esforço aplicado em forma de trabalho, servindo de fundamento para medir a importância correspondente a cada bem e a quantidade de excesso de valor, ou mais-valia, cobrada em cada produto, sendo esta a característica marcante da sociedade capitalista, como conceituada por Barradas (2014, p. 131):

O mais-trabalho objetivado, ou trabalho excedente - a mais-valia -, nada cria em termos de desenvolvimento ou valor para a vida do trabalhador. A jornada de trabalho congrega esses dois momentos da produção capitalista: a parte de tempo em que o trabalhador produz a reposição de sua força de trabalho e a parte em que ele despende mais-trabalho e produz a mais-valia para o capital.

A busca pela maximização da mais-valia é a denominada "lógica capitalista", que interfere na própria forma de organização do trabalho e, em especial, no processo manufatureiro.

A análise de Marx (2013, p. 514) sobre a manufatura permite que se observe uma transformação da divisão social do trabalho, que abandona o caráter tribal ou familiar em prol de uma organizaçáo unilateral, em que o processo de especialização é essencial, introduzindo o que conhecemos por divisão social do trabalho, utilizando-se, para tanto, da combinação de diversos ofícios em um mesmo posto. Atualmente, a sociedade enfrenta um processo de expansão dessa divisão social do trabalho, com uma crescente complexificação das relaçóes laborais, o que se materializa com a crescente especialização das atividades, vinculando-se à ideia de "mercadorizaçáo" das relaçooes humanas e, consequentemente, de flexibilização das relações trabalhistas, o que pode ser evidenciado nas palavras de Huws (2015, p. 46): 
De fato, em alguns casos, o processo pode parecer com dar zoom num fractal, uma descida em círculos cada vez menores dentro de outros círculos semelhantes, com a aparente inventividade interminável do capital, em que cada área da atividade se torna a base para novas mercadorias capazes de produzir lucro.

A “mercadorização" é importante, como afirma Huws (2015, p. 38), devido à sua influência intrínseca na organização da produção e na estrutura do mercado (organização do consumo), vez que sua atuaçáo é inerente à relação de compra de mercadoria e venda de força de trabalho. Antunes (2014, posição 65\%) também defende essa posição, afirmando que as atuais conjecturas das relaçóes laborativas provocaram, na classe trabalhadora, uma fragmentação, uma heterogeneização e uma complexificação, que se fundamentam em dois efeitos distintos. Primeiramente, em menor escala, houve uma intelectualização do trabalho, como se verifica, por exemplo, no ramo da siderurgia, que é responsável por tornar o trabalhador polivalente e multifuncional, permitindo que ele realize diversas funções por intermédio das máquinas, assim como, que assuma postos de supervisão e de regulação dos processos produtivos. Em segundo, e em maior escala, houve a precarização e a desqualificação da classe trabalhadora, com a perda progressiva de importância das suas funçóes dentro da cadeia produtiva, o que facilita a sua substituição, em busca de menores custos.

Esta nova forma de observar a divisão social do trabalho é evidenciada por meio do surgimento de uma nova classe proletária, o "cibertariado" (HUWS, 2015, p. 48).

\section{O sistema capitalista de produçáo e o mercado flexibilizado: o cibertariado}

A formação da sociedade industrial e o surgimento do capitalismo ocorreram em decorrência da primeira Revolução Industrial, na Inglaterra, por volta de 1820 a 1840, e com a segunda Revoluçáo Industrial, nos anos de transiçáo entre 1840 e 1870. A partir de então, sucederam-se práticas administrativas e gerenciais voltadas à maximização dos lucros, como estratégias para a reprodução do capital, destacando-se, entre elas, o Fordismo e o Toyotismo.

O Fordismo surgiu em 1914, quando Henry Ford instituiu a jornada de trabalho limitada a 8 horas e a recompensa de 5 dólares para os trabalhadores da linha de produção de automóveis, em sua fábrica instalada em Dearbon, Michigan. O sistema fordista corresponde a um conjunto de práticas administrativas e gerenciais que objetivam uma reestruturação do sistema de produção, com o intuito de maximizar os lucros. Na seara administrativa, é caracterizado por sua estrutura vertical, por qual toda, ou grande parte, da sua cadeia produtiva tende a ser concentrada em uma única empresa, desde a aquisição de matérias-primas, até a confecção do produto, favorecendo uma grande necessidade de trabalhadores nas fábricas. O Fordismo é também conhecido pela utilização da linha de montagem, que torna desnecessário o deslocamento do trabalhador até o produto, com 
a aplicação de funções rotineiras, simplificadas e por um fluxo progressivo e contínuo de partes e de peças, evitando o desperdício de tempo e de dinheiro (LARANJEIRA, 2002, p. 123).

A diminuição da autonomia e a roteirização das atividades, características do sistema fordista, foram as responsáveis pelo surgimento dos movimentos de resistência e por greves operárias (ROSSO, 2017, p. 22), resultando em baixa produtividade nas indústrias, no aumento do número de peças defeituosas, na sabotagem, nas paralisaçóes, na alta rotatividade dos empregos, entre outros (BOTELHO, 2008, p. 34). Um dos símbolos desses movimentos de resistência foi o fortalecimento dos sindicatos (HARVEY, 1989, p. 123).

Essas condições de trabalho fez com que as empresas e os trabalhadores entrassem em choque, principalmente, em decorrência dos efeitos da Grande Depressão, nos Estados Unidos da América, em 1929, que tornou real o risco de colapso de todo o sistema capitalista, sendo caracterizada como uma crise de superprodução, originada pela reestruturação dos países europeus e pela perda, por meio dos Estados Unidos da América, de parte considerável desse mercado consumidor, ocasionando a impossibilidade de escoamento dos seus produtos.

A partir dessa fase, o Estado americano passou a intervir na economia, o que foi materializado pelo New Deal, a política adotada pelo presidente americano Franklin Roosevelt, baseadas nas ideias keynesianas, que buscou, com a regulação estatal, reestruturar o mercado norte-americano e o capitalismo como um todo (HARVEY, 1989, p. 124). Em que pese esses esforços, as empresas permaneciam com parte de sua capacidade produtiva ociosa, em razão da perda de mercado e da escassez de matériasprimas, o que acarretou em modificaçóes no modelo de competiçáo mundial, com a diminuição de custos, com a busca por maior competitividade e pela introdução de novos padróes gerenciais e administrativos, o que obrigou as empresas a entrar em um período de racionalização, reestruturação e intensificação do controle do trabalho (HARVEY, 1989, p. 137).

Com isso, o sistema capitalista de produção, utilizando-se do modelo fordista e das políticas intervencionistas, alcançou o seu "ponto de equilíbrio", caracterizado pela estabilidade econômica e pelo crescimento social, marcando um período que ficou conhecido como "Anos Dourados" do Capitalismo, iniciado por volta de 1945. No status social, essa relação também foi acentuada, com a maturação da ideia de pleno emprego, que era reforçada pelos sindicatos, que estavam cada vez mais presentes e assumindo o seu papel de fiscal da ordem trabalhista. Sua duração, entretanto, não foi longínqua, o que foi evidenciado com a Crise do Petróleo de 1970 e com a alta inflação do dólar (HARVEY, 1989, p. 135). 
A crise de 1970 contribuiu para que a flexibilização ganhasse força no mercado, colocando em alerta as conquistas das décadas anteriores e permitindo a ascensão de um novo modelo produtivo, o Toyotismo. Esse modelo não apresentava como diferencial o processo de automação, pois a linha de montagem já era uma prática fordista, mas esse papel coube à desconcentraçáo do processo produtivo e às novas técnicas gerenciais, que permitiram se instrumentalizar a produzir em decorrência da demanda efetiva do mercado, e não para atender à especulação, o que possibilitou a extinção dos grandes estoques e a redução dos custos de produção.

Esse sistema, o Toyotismo, funciona por meio de um fluxo contínuo de produção, que prioriza o número mínimo de pessoas e insumos, admitindo que as metas sejam adequadas quando houver baixa demanda efetiva, de modo a náo haver tempo ocioso para o trabalhador, nem, tampouco, a criação de estoque. Elevando-se a demanda, cada trabalhador assume novas metas, para que abranja o número máximo de postos que consiga suportar (PINTO, 2013, p. 68), sendo conhecido como como just in time e significa "produzir somente o que é necessário" (PINTO, 2013, p. 69).

O novo processo permitia a busca do lucro a partir da flexibilização do trabalhador e do espaço produtivo, apresentando como resultados o crescimento do desemprego estrutural, a reciclagem das habilidades manuais, a estagnação ou a diminuição dos aumentos salariais e o retrocesso do poder sindical (HARVEY, 1989, p. 141).

A flexibilidade não se direciona apenas à eliminação de estoques ou a maleabilidade do trabalhador, que se torna polivalente, mas visa à reconfiguraçáo da cadeia produtiva das empresas, que deixam de se organizar em uma hierarquia vertical e assumem uma nova hierarquia horizontal. Com isso, passam a não reunir toda a cadeia produtiva em um único "espaço", mas criam um rol de relaçóes e parcerias que atendem as demandas, sendo o que Castells (2005, p. 219) denomina de "estrutura em rede". Neste sentido, Mannrich (2010) afirma que:

Nas grandes corporações da atualidade, observa-se a externalização do processo produtivo, integrado por meio de redes empresariais cuja complexidade de suas estruturas nada guarda da antiga concepção. As empresas tradicionais cedem espaços às integradas em grupo. Tais transformaçôes resultam de mercados internacionalizados, com exigência de grandes inversôes e extraordinária evolução tecnológica.

A reorganização produtiva constituiu uma resposta à crise de "sobreacumulação", consagrando um novo padrão de eficiência e de produtividade, ganhando força, principalmente, nos países com industrialização tardia, como o Brasil (COUTINHO, 2015, p. 111). O marco central dessa nova realidade é a existência dos contratos de trabalho flexíveis, como o part time, o contrato por empreitada, as jornadas de trabalho flexíveis, que, no Brasil, foram permitidos pela reforma trabalhistas, Lei no 13.429/2017 (BRASIL, 2017). 
Esses fatos demonstram como a divisão social do trabalho tornou-se mais complexa e, ainda, que uma de suas principais consequências foi a crescente "mercadorização" das relaçóes humanas, o que vem afligindo o mercado e impactando, em especial, as atividades de serviços (HUWS, 2015, p. 46).

A “mercadorização" consiste em colocar no mercado diversas atividades econômicas que anteriormente estavam fora da sua abrangência, principalmente no que concerne à prestação de serviços, que é volátil, se modificando a cada momento, a fim de acompanhar as inovaçóes e as necessidades do mundo globalizado. Assim, foram transformadas em serviços as atividades que eram vistas como inerentes à cadeia produtiva das empresas, a exemplo do telemarketing, o qual atualmente pode ser independente.

Importante destacar que tal "mercadorização" e a crescente complexidade da divisão do trabalho se sobressaem quando analisamos a ampla influência das Tecnologias da Informação e Comunicação (TIC's) e suas consequências diretas para a "Divisão Digital" (HUWS, 2015, p. 38), por três causas principais. Como primeira, temos o unbundling, ou efeito desagregador, que é vinculado à automação dos escritórios, atuando em conjunto com a precarização das relaçóes trabalhistas, tais como as políticas públicas de mitigação da proteção laboral (como as reformas propostas pelo Brasil, Portugal e Reino Unido) e o estímulo à privatização dos serviços públicos. Como segunda causa temos a capacidade das TIC's de externalizar os processos de trabalho, ou seja, a capacidade das empresas de transferir, por meio da automação, determinadas atividades diretamente aos usuários, excluindo agentes intermediários (HUWS, 2003, p. 57), o que pode ser observado em agências de turismos e bancos. A terceira causa a ser citada é o teletrabalho, que ainda está em processo de ampliação, mas que já pode ser constatado em cursos online, em que o mesmo profissional é o responsável pelo ensino em diversas regióes de um país ou do mundo.

Huws (2015, p. 47) destaca que os efeitos combinados da privatização, da desagregação de grandes organizaçóes em suas partes constituintes, da convergência entre setores, da propriedade cruzada e da integração vertical, propiciaram uma nítida confusão entre os setores primários, os secundários e os terciários da sociedade, assim como entre os setores públicos e privados, ampliando o grau de complexidade das próprias relaçóes laborais. Esse novo modelo, centrado em demandas da informação e da comunicação, demarca a inserção definitiva da informática como ponto central na cadeia produtiva, de modo a gerar novas formas de controle e exploração do proletário, sendo imposta, por consequência, uma nova lógica de acumulação do capital, instrumentalizada por meio de intensas rotinas de trabalho (normalmente estabelecida por meio de metas) e pela exigência de qualificação profissional constante e ampla (ARAÚJO; FARIAS, 2016, p. 208). 
Essa análise não se fundamenta na extinção de antigos serviços e na sua consequente substituição por novas e "modernas" atividades, mas sim pelo crescente grau de complexidade que se verifica nas inter-relaçóes dos atores envolvidos no processo de produção, ou na própria cadeia global de produção. Isso pode ser observado pelo modo como as empresas vêm efetuando sua reorganização interna, em que a terceirização adquire papel fundamental, constatando-se a segregação de uma empresa em diversas outras, as quais passam a se interligar por meio de contratos e acordos comerciais, negociados e renegociados continuamente, criando centros de lucro ou a interdependência de custos. Essa nova divisão apresenta, também, novos atores, como a "classe-que-vive-do-trabalho", que inclui a totalidade dos trabalhadores que vendem sua força de trabalho (ANTUNES, 2014, posição 33\%).

Estes atores ampliam o conceito de classe trabalhadora, proposto por Marx, uma vez que nela se incluem atividades que, "apesar de produzirem mais-valia, não são diretamente manuais" (ANTUNES, 2014, posição 34\%), não sendo composta apenas por trabalhadores produtivos, mas sim por uma relação viva entre os trabalhadores produtivos e os improdutivos (ANTUNES, 2014, posição 34\%), que, segundo Antunes (2014, posição 34\%):

[...] inclui, então, todos aqueles e aquelas que vendem sua força de trabalho em troca de salário, incorporando, além do proletariado industrial, dos assalariados do setor de serviços, também o proletariado rural, que vende sua força de trabalho para o capital. Essa noçáo incorpora o proletariado precarizado, o subproletariado moderno, part-time, o novo proletariado dos McDonald's, os trabalhadores hifenizados de que falou Beynon, os trabalhadores terceirizados e precarizados das empresas liofilizadas de que falou Juan José Castillo, os trabalhadores assalariados da chamada "economia informal", que muitas vezes são indiretamente subordinados ao capital, além dos trabalhadores desempregados.

A partir desse conceito amplo de proletariado, que engloba diversas camadas sociais influenciadas pelos efeitos da nova divisão do trabalho, como o "cibertariado", se identifica os novos e legítimos representantes do grau evolutivo do processo de globalização. A importância do "cibertariado", inclusive, é revelada pelo desenvolvimento de sua cadeia produtiva, que possibilita a identificaçáo das modificaçóes inerentes aos modelos fordistas e tayloristas de produçáo, outrora mencionados. Assim, essa nova classe enfrenta a inserção mais assídua e incisiva da informática dentro do modelo de produção do capital, abarcando, de forma mais imediata, os efeitos da terceirização na sociedade, como a menor rentabilidade do labor e a desconfiguraçáo de um ambiente de trabalho sustentável e decente.

\section{A terceirizaçáo e os seus reflexos no mercado}

A terceirização, como um dos instrumentos da flexibilização do mercado, é defendida, por alguns autores, como uma importante aliada no combate ao desemprego 
estrutural e ao capitalismo excludente, ao argumento de que garantiria o crescimento na quantidade de empregos e nas oportunidades disponíveis à sociedade. No entanto, os resultados obtidos afastam-na desse fim, o que não é revelado somente por parâmetros quantitativos, mas também em termos conceituais, uma vez que a terceirização deveria combater o desemprego estrutural, mas tem apresentado resultados diversos, como a extinção de postos de trabalho e a precarização do mercado (POCHMANN, 2011).

Para Neto (1995, p. 4), a terceirização consiste na transferência de parte ou de toda as funções do departamento de uma "empresa-origem", para empresas subcontratadas, que são denominadas de "empresas-destino", sendo que sua abrangência vai depender da necessidade da primeira, vez que poderá incluir etapas do processo produtivo (essencial para a formaçáo da mercadoria) ou, apenas, as atividades ou serviços de apoio, como limpeza, vigilância e afins. Nela, a relação empregatícia é caracterizada pela inserção de uma terceira persona, tornando-a trilateral, enquanto que o vínculo de emprego "comum" é, essencialmente, bilateral, o que provoca uma dissociação entre a relação econômica de trabalho, constituída com a empresa tomadora e a relação jurídica empregatícia, vinculada à empresa terceirizante, de modo a provocar desajustes às normativas e aos objetivos protecionistas do Direito do Trabalho (DELGADO, 2015, p. 503).

O processo de terceirização da cadeia produtiva, no Brasil, iniciou-se na década de 1960, tendo como enfoque o serviço público e, posteriormente, o privado (IPEA, 2016, p. 7). A Consolidaçáo das Leis do Trabalho - CLT (BRASIL, 1943), originariamente, fazia menção a duas figuras de subcontratação de mão de obra, a empreitada e a subempreitada, no seu artigo 455, de modo a englobar também a pequena empreitada, prevista no artigo 652, alínea a, inciso III, da CLT, o que a diferenciam do que se entende por terceirização, na atualidade.

Essa noção incipiente da terceirização manteve-se até o fim da década de 60, a partir da qual foi ampliada e inserida no segmento estatal do mercado, por meio do Decreto Lei no 200/67 (BRASIL, 1967) e da Lei no 5.645/70 (BRASIL, 1970). Na década de 70, ela se tornou mais agressiva, inserindo-se no campo privado, por meio da Lei no 6.019/74 (BRASIL, 1974), que regulou o trabalho temporário e da Lei no 7.102/83 (BRASIL, 1983), que autorizava a terceirização na vigilância bancária, sendo ampliada com as alteraçóes advindas da Lei no 8.863/94 (BRASIL, 1994), que aumentou o rol de funções que poderiam ser terceirizadas (DELGADO, 2015, p. 503).

A promulgação da Lei no 8.949 (BRASIL, 1994) também foi marcante para a ampliação da terceirização, vez que acrescentou um parágrafo único ao artigo 422 da CLT, introduzindo o que podemos considerar uma nova forma de terceirização, camuflada sob a denominação de cooperativa (DELGADO, 2015, p. 504). Essa expansão trouxe consequências e litígios, que, submetidos ao judiciário trabalhista, entre as décadas de 80 e 90, deram ensejo à edição das súmulas de no 256 (BRASIL, 1986) do Tribunal Superior 
do Trabalho (TST), e, posteriormente, a de número 331 do TST (BRASIL, 1993), que perdura, apesar de alterada, até hoje.

A Súmula no 331 (BRASIL, 1993) apresentava o condáo de limitar o processo de expansão da terceirização, até 2017 , vez que vedava expressamente sua utilização nas atividades-fim da empresa, de modo que só seria lícita a terceirização de atividades-meio. Em 2017, aproveitando o texto da Lei no 6.019 (BRASIL, 1974), que regulava a locação de mão de obra, o legislador introduziu, por meio das Leis n. ${ }^{0} 13.424$ (BRASIL, 2003) e 13.467 (BRASIL, 2011), um novo regime de terceirização, ampliando a sua possibilidade para qualquer atividade, quer seja fim, quer meio, da empresa contratante.

O IPEA (2016, p. 16) estimou o montante de 1.997.118 trabalhadores assalariados em possível contratação terceirizada, identificados dentro de 17 subatividades, constantes da Classificação Nacional de Atividades Econômicas (CNAE). Os dados levam em consideração as empresas que fornecem a Relação Anual de Informações Sociais (RAIS) de seus empregados, ou seja, que cumprem a sua obrigação legal. Esses dados refletem a terceirização interna ou triangular, não conseguindo abarcar toda a terceirização da cadeia produtiva, em amplitude global, nem as relaçóes informais, que se encontram à "margem da sociedade".

Os efeitos da terceirização são sentidos pelos trabalhadores, impondo, por um lado, menores remuneraçóes, e, por outro, crescentes metas. Quanto a remuneração, segundo o IPEA (2016, p. 26), sofreu redução de 49\%, para os vendedores; de 18,4\%, para os cozinheiros; de 17,8\%, para os assistentes administrativos; de 16,8\%, para os serventes de obra; de 13,9\%, para os auxiliares de escritório; de 12,2\%, para os motoristas de caminhão; de 11,6\%, para os trabalhadores de limpeza pública e de 11,5\%, para os recepcionistas.

Coutinho (2015, p. 118) também constata uma diferença marcante de remuneraçáo, entre os trabalhadores próprios (integrante da tomadora de serviços) e os terceirizados, em desfavor dos últimos, afirmando que um dos pontos relevantes que a provoca é o declínio da proteção sindical, que decorre do diferente enquadramento sindical dos trabalhadores terceirizados, normalmente vinculados ao comércio. A variação de remuneração foi observada, igualmente, entre os trabalhadores que realizam atividades bancárias, revelando-se pelo fato de que, em 2009, o piso salarial de um terceirizado era de $\mathrm{R} \$ 555,00$ (quinhentos e cinquenta e cinco reais), enquanto que o de um trabalhador próprio era de $\mathrm{R} \$ 1.010,64$ (mil e dez reais e sessenta e quatro centavos). Coutinho (2015, p. 139) frisa que a jornada diária dos primeiros era de até 9 horas e 48 minutos, enquanto a dos últimos era de 6 horas. Em termos relativos, o trabalhador terceirizado ganha o equivalente a $R \$ 1,9$ reais por hora de trabalho, enquanto a do trabalhador próprio equivale a $\mathrm{R} \$ 5,61$ reais, ou seja, é, aproximadamente, três vezes menor. 
Em complemento a esses dados o autor destaca a diferença salarial entre os trabalhadores do setor de combustível, Petrobrás, próprios e terceirizados. Os primeiros apresentavam salário médio de $\mathrm{R} \$ 2.800,00$ (dois mil e oitocentos reais), direito ao auxíliorefeição de $\mathrm{R} \$ 600,00$ (seiscentos reais), participação nos lucros de, aproximadamente, $\mathrm{R} \$ 17.000,00$ (dezessete mil reais) e horas extras, com acréscimo de 100\% a 150\% sobre a hora regular. Quanto aos terceirizados, o salário médio era de R\$1.300,00 (mil e trezentos reais), o auxílio-refeição era de $\mathrm{R} \$ 291,00$ (duzentos e noventa e um reais), não havia participação nos lucros e as horas extras eram calculadas com acréscimo de $50 \%$ a $100 \%$ sobre a hora regular (COUTINHO, 2015, p. 141). Por conseguinte, o DIEESE (2017, p. 9) identificou que essa diferença é sentida principalmente nos setores com remuneraçóes mais elevadas, sendo que os de menor remuneraçáo se equivalem. Observou, ainda, a presença elevada de discriminação quanto ao sexo para a definição das remunerações, visto que os homens, em atividades terceirizadas, foram identificados em uma estratificação superior, em comparação a das mulheres (DIEESE, 2017, p. 10).

Iniciando certa divergência, Stein (2017) chega a uma conclusão diferenciada, avaliando que essa variação salarial seria de 3,6\% negativa, entre o trabalhador terceirizado e o próprio (empregado da empresa), cabendo destacar que a base encontrada é heterogênea, ou seja, para os serviços como limpeza e telemarketing a diferença salarial é negativa, enquanto para os de segurança e vigilância, a variação é positiva (STEIN et al, 2017, p. 590). Para explicar essa diferença o autor (STEIN et al, 2017, p. 597) destaca o fato de os trabalhadores terceirizados serem, em média, três anos mais novos e ficarem menos tempo em um mesmo emprego, concluindo que a diferença de remuneração entre os trabalhadores terceirizados e os próprios se revela mínima, quando comparada a outras pesquisas realizadas sobre este tema. Barreto Júnior (2012, p. 91), contudo, discorda desta conclusão, destacando evidências da perda de $40 \%$ da remuneração dos trabalhadores de telemarketing no sistema bancário, levando-se em consideração sua parte fixa e variável (participação nos lucros ou resultados e vale alimentação), com a transferência destes para as empresas terceirizadas. Essa análise também foi realizada por Sanches (2013, p. 43), o qual afirma que no setor bancário, os prestadores de serviços, incluindo os terceirizados, recebem o correspondente a um terço da remuneração dos empregados próprios para executar as mesmas funções, mas com jornadas estendidas.

Como afirmam Antunes (2014) e Cavalcante (2010), esses efeitos são identificados no "cibertariado", em especial, em relação aos atendentes de telemarketing, o que se justifica por sua ligação direta com a terceirizaçáo, incluindo seus principais resultados, como a imposição de metas crescentes, o controle de jornada, a perda de representatividade sindical e a desconsideração dos limites físicos da pessoa humana, de modo a subjugála a padrões de trabalho não decentes. Nascimento (2007, p. 16) reforça essa ideia, ao ressaltar que a remuneração média dos gerentes do telemarketing, nos call centers próprios 
de empresas, é de $\mathrm{R} \$ 58.700,00$, por ano, e nas empresas terceirizadas essa média cai para $\mathrm{R} \$ 42.700,00$.

Quanto aos sindicatos, Brito Filho (2018, p. 88) afirma que o Brasil vive em um sistema híbrido, marcado por traços de uma liberdade sindical (liberdade de associação e administração) e, de outro lado, por restrições às liberdades coletivas de organização (unicidade sindical, base territorial mínima e afins). Essa características rígidas, por consequência, entram em choque com a "nova" sociedade globalizada e flexibilizada, o que é constatado pelo IPEA (2014, p. 22), ao afirma que os sindicatos brasileiros passam por uma crise oriunda, em especial, da queda de filiaçóes e da perda da obrigatoriedade da contribuição sindical, a partir da Lei no 13.467/2017 (BRASIL, 2017), que alterou o artigo 545 da CLT.

Esse processo tornou imperioso que os sindicatos readequassem a sua atuaçáo, haja vista que a flexibilizaçáo dos mercados retirou grande parte dos trabalhadores das fábricas, provocando sua reunião em grupos menores (empresas terceirizadas) ou promovendo uma dificuldade no reconhecimento da sua "classe", vez que passaram por um processo de descentralização, de reclassificação e de enfraquecimento coletivo. Assim, ainda que os ex-empregados próprios sejam recontratados pelas empresas terceirizadas, estes perdem o seu antigo enquadramento sindical (deslocamento sindical), passando a integrar, principalmente, o comércio, ramo no qual localiza-se a maioria das empresas de prestação de serviços, como, a título de exemplo, é observado no setor bancário. Em contrapartida, esse movimento de deslocamento provocou o surgimento de um novo grupo, bastante numeroso, apesar de ainda desorganizado, a saber, o "novo proletariado de serviços" (ANTUNES, 2018, p. 294).

A partir dessa realidade torna-se urgente que os sindicatos congreguem o "novo proletariado de serviço", representado pelos trabalhadores do telemarketing, dos supermercados, do comércio, das indústria hoteleira e afins, que nunca tiveram tradição de uma organização sindical forte, mas que, devido ao seu papel crescente no mercado, deverão ser introduzidos para que se alcance uma estabilidade (ANTUNES, 2018, p. 295).

Esse processo de flexibilização, instrumentalizada por meio da terceirização, não é um fenômeno que atinge somente a remuneração do trabalhador, mas influência também na oferta de justas condições de trabalho, que não são cumpridas ou são mitigadas. A título de exemplo, em 2008, a taxa de mortalidade vinculada aos trabalhadores do setor elétrico chegou ao patamar de 32,9 mortes, por grupo de 100 mil trabalhadores, sendo identificado uma taxa 3,21 vezes superior entre os trabalhadores terceirizados (KOURY, 2014, p. 62). O mesmo pode ser verificado no novo proletariado de serviços, com destaque aos trabalhadores de telemarketing, com inegáveis prejuízos à sua saúde, seja por 
uma jornada exaustiva, seja pela imposição de metas excessivas, que ignoram os limites da condição humana, o que será demonstrado.

Como primeira causa para essa precarização, constatada no segmento do telemarketing, Araújo (2013, p. 93) identifica a realizaçáo de tarefas repetitivas, a falta de autonomia do trabalhador, as altas cargas de trabalho e a elevada rotatividade, derivada, em parte, de auditorias constantes. Destaca que esse modelo mantém características mistas entre as práticas fordistas e as flexibilizadas, apresentando a ampla exploraçáo do trabalhador e o prejuízo à sua saúde como uma das suas consequências, que se evidencia pela dificuldade para dormir, pelo nervosismo, pelos sonhos com o trabalho, pelas dores de cabeça constantes, dentre outros sintomas que favorecem o desenvolvimento do estados de apatia, de insatisfaçáo, de fadiga, de ansiedade, bem como lhes infligem distúrbios psicossomáticos de maior gravidade (ARAÚJO, 2013, p. 94). Outros problemas identificados no telemarketing foram: o ressecamento da garganta, o cansaço, a rouquidão, o pigarro constante, a falta de ar, a tosse constante, a dor ao falar e ao engolir, a afonia e a voz forte, soprosa ou tensa, além dos de ordem psicossomáticas, como a depressão (ARAÚJO, 2013, p. 94).

No telemarketing esses problemas são agravados devido à perda da comunicação pessoal ou da sua transformação em impessoal, pelo aparato de interface técnica e dos scripts, roteiros obrigatórios, repassados sob pena de puniçóes, que náo permitem a expressão de emoçóes ou de sentimentos pelos trabalhadores, nem mesmo para o alívio do esforço mental, trazendo sofrimento físico e psíquico e tornando-os cada vez mais solitários e destituídos de suas identidades (ARAÚJO, 2013, p. 94). A influência negativa desse controle de emoçóes reflete no desempenho, na produtividade e na saúde dos trabalhadores do telemarketing, o que se agrava devido às condiçóes físicas a que estão submetidos, como as restriçóes às necessidades fisiológicas, à perda da audição devido a utilização de headset, à posturas inadequadas e aos prejuízos na voz, decorrentes da associação entre a fala constante e o ar-condicionado (TAKAHASHI et al, 2014, p. 339).

Nos call centers, centros para a atuação dos atendentes de telemarketing, observa-se que a incidência de adoecimentos é superior à média do mercado de trabalho, sendo maior nas empresas terceirizadas, em comparação com as que integram o serviço a sua cadeia produtiva, apesar de a proporção de ocultamentos também ser superior (FILGUEIRAS, 2014 , p. 6). Essa conclusão é reforçada por Almeida (2009, p. 30), ao afirma que, entre 2003 e 2005, 1.107 trabalhadores de call centers foram afastados do seu emprego, sendo $45 \%$ desses afastamentos relacionados a doenças osteomusculares, como a síndrome do Túnel do Carpo e Lesões por Esforço Repetitivo (LER).

No telemarketing, além disso, se observa o aumento do número de suicídios, como se constatou na França, onde a empresa France Télécom, maior empresa do segmento no país, com cerca de 102.000 trabalhadores, registrou quatro suicídios em 2004 e 34, entre 
janeiro de 2008 e janeiro de 2010 (VENCO et al, 2010, p. 4). Venco (2010, p. 6) destaca três elementos que permitem compreender a relação entre o suicídio e o mercado de trabalho, a saber: o estresse, que consegue associar as perturbaçóes biológica e psicológicas ao ambiente de trabalho; a fragilidade individual, que tem como base o histórico de doenças já existentes; e os aspectos sociogenéticos, que analisam características vinculadas ao trabalho, como fatores de descompensação psicológica.

Observa-se que o novo proletariado de serviços é severamente afetado pelos efeitos que a nova divisão do trabalho impóe, degradando a remuneraçáo e a própria vida do trabalhador, por meio de piores condiçóes de trabalho, o que confronta a noção do mínimo que deve ser garantido no "mundo do trabalho", seja por meio da regulação estatal, seja com a consagração dos direitos humanos, ou por ambos, o que é materializado através da ideia de trabalho decente e, em especial, da sua noção de justa remuneração, justas condições de trabalho, direito ao trabalho e liberdade sindical (BRITO FILHO, 2013, p. 49).

Para que se entenda o trabalho decente é necessário observar uma série de requisitos, ora em âmbito individual, ora coletivo. Na seara individual, deve-se observar cinco requisitos para a configuração de um trabalho decente, a saber:

A prevalência do social, e não do capital, nas políticas públicas, haja vista o argumento oposto permitir que se criem discursos a favor da mitigaçáo das condiçóes trabalhistas, em prol da inserçáo dos desempregados no mercado, favorecendo a concentração de riquezas e as desigualdades, e não a criação de empregos (BRITO FILHO, 2013, p. 50).

Como segundo requisito temos a liberdade de escolha do trabalho, sendo defesa sua sujeição obrigatória, vez que fere um dos princípios básicos de um Estado Democrático de Direito, a liberdade. (BRITO FILHO, 2013, p. 50). A liberdade é um direito fundamental a ser resguardado pelo Estado e pela sociedade e, por isso, deve ser incluída dentro do rol de direitos laborais. Não há como analisar o trabalho, como fonte de desenvolvimento humano, se este não for de livre escolha, for justo, for adequado e for desenvolvido dentro dos parâmetros de um trabalho decente e digno.

A igualdade de oportunidade no exercício do trabalho é o terceiro requisito, vez que protege o trabalhadorde medidas discriminatórias, tanto para o seu ingresso noambiente empresarial, quanto para a sua promoção (BRITO FILHO, 2013, p. 51). O direito à não discriminação, intrínseco ao terceiro requisito, é fundamental na relação laboral, haja vista envolver o ingresso, a manutenção e a promoção do trabalhador. Não temos como falar em livre escolha do trabalhador ou na existência de trabalho digno, se o trabalho for permeado por medidas discriminatórias, que impeçam ou dificultem sua integral prestação. 
O quarto requisito é o direito de exercer o trabalho em condições que preservem a saúde do trabalhador. É uma preocupação fundamental, mas que ganhou importância há pouco tempo, consoante a qual a preservação da vida e da saúde do trabalhador deve ser ponto essencial dentro da relação de trabalho (BRITO FILHO, 2013, p. 51). A degradação no ambiente de trabalho é identificada de diversas maneiras, como na exposição do trabalhador a agentes químicos, a ruídos severos, a jornadas intercaladas maçantes e afins. Todavia, o que se deve garantir é que o trabalhador sofra o menor dano físico possível no exercício de sua profissáo e, de preferência, que a utilização de instrumentos, como os Equipamentos de Proteção Individual (EPI), reduzam os danos a patamares aceitáveis, que não provoquem prejuízos ao trabalhador, nem no presente, nem no futuro.

O quinto ponto a ser debatido é o direito a uma justa remuneração, que não envolve apenas o direito ao pagamento do serviço prestado, mas também exige que este seja proporcionalàtarefaesuficienteaosustentodotrabalhadoredeseusdependentes, devendoser considerado um dos principais direitos econômicos da segunda dimensão dos Direitos Humanos (BRITO FILHO, 2013, p. 52).

Como penúltimo quesito, temos o "direito a justas condições de trabalho, principalmente a limitação de jornada de trabalho e a existência de períodos de repouso" (BRITO FILHO, 2013, p. 52). A náo existência de limites para a exploraçáo do trabalhador, principalmente em situaçóes adversas ao pleno emprego (como no período fordista e na atual realidade do mercado brasileiro), permite que o tomador de serviços explore-o ao máximo, de modo que consiga obter a maior lucratividade possível naquela relação, principalmente devido à subordinação "forçada" do empregado, que se sujeitará a qualquer condição imposta pelo mercado para poder se sustentar.

Porúltimotemosa proibiçãodotrabalho infantil, quesedáemduasfrentes. Aprimeira faz referência ao trabalho infantil em si, uma vez que prejudica o desenvolvimento do ser humano. A segunda refere-se a garantir condiçóes para que as famílias possam subsistir sem a necessidade da participaçáo infantil, o que ocorre por intermédio das políticas públicas, como o benefício de prestação continuada. (BRITO FILHO, 2013, p. 53).

Esse rol fundamenta, no plano individual, os requisitos necessários para que se materializeo "trabalhodecente" nasociedade, permitindoodesenvolvimentodotrabalhadore a existência de uma vida laboral que não o submeta a situações degradantes. Contudo, é necessário destacar a existência de um quesito do plano coletivo, qual seja, a liberdade sindical, vez que ela possibilita a reuniáo dos trabalhadores na luta pelos direitos coletivos, permitindo-lhes "organizar associações e, nelas, decidir quais as linhas de ação mais convenientes para a defesa de seus interesses, ocorrer em clima de liberdade, com proteção para aqueles que recebem o encargo de representar os trabalhadores" (BRITO FILHO, 2013, p. 54). 
Como observado, a flexibilização nas novas atividades de serviços vem desrespeitando diversos requisitos necessário para a configuração de um trabalho decente, tornando-os menos sustentáveis aos trabalhadores, o que é constatado pela queda das remuneraçóes e das justas e adequadas condiçóes de trabalho, no plano individual, ou o enfraquecimento dos sindicatos, no plano coletivo, como demonstrado nessa seção.

\section{Consideraçóes finais}

O problema que se buscou resolver nesta pesquisa é se a flexibilização do mercado provoca a precarização do trabalho, em especial, em relação ao novo proletariado de serviços. Como demonstrado na Seção 1, a atual divisão do trabalho não se limitada às características definidas por Marx (2013), principalmente pelo efeito da flexibilização do mercado e da" mercadorização" das atividades. Essa nova relaçáo, conforme a Seção 2, permitiu o reconhecimento da "classe-que-vive-do-trabalho", como símbolo de uma parcela da sociedade que produz mais-valia, mas que não atua com o trabalho manual, sendo representada pelo "cibertariado". A partir desse reconhecimento identifica-se a "nova divisão do trabalho", ampliando o conceito originalmente delimitado por Marx (2013), para adequá-lo a uma nova realidade flexibilizada.

O foco do estudo no "cibertariado" permitiu que se responda à questão problema, vez que esse grupo, integrado entre outras categorias pelos atendentes de telemarketing, permite o reconhecimento dos efeitos da flexibilizaçáo no mercado, assim como a transição do modelo de produção fordista para o taylorista e a precarização das relaçóes trabalhistas.

Quanto a transição dos modelos de produção observamos a flexibilização do trabalhador, tornando-o polivalente e adaptável as metas do mercado e do espaço produtivo, de modo a atuar sob a efetiva demanda, para tornar desnecessário grandes estoques e, consequentemente, reduzindo os custos da produção. Essa transição, todavia, reformulou a estrutura da hierarquia vertical da administração das empresas, fazendo com que a concentração da produção na mesma cadeia produtiva fosse desnecessária, passando a atuar por meio de contratos comerciais e de parcerias, o que foi possível por meio de instrumentos de flexibilização, como a terceirização, que constitui o que Castells (2005) denomina de "estrutura em rede". Como resultado constatou-se a precarização das relaçóes trabalhistas, por meio dos efeitos da terceirização no mercado, em especial no setor do telemarketing, o que foi realizado na terceira seção desta pesquisa.

Essa precarização teve influência tanto na queda da remuneraçáo, quanto no enfraquecimento sindical do trabalhador, como observado nas pesquisas de Coutinho (2015), Barreto Júnior (2012), Silva (2002) e Nascimento (2007), assim como em relação à inexistência de justas condiçóes de trabalho, como destacado por Araújo (2013), 
Takahashi (2014) e Almeida (2009). Com esses resultados tornou-se possível identificar a precarização das novas atividades de serviços, em especial a de telemarketing, por não satisfazer condições mínimas de dignidade na relação de trabalho, materializada por meio da noção de trabalho decente, como compreendida por Brito Filho (2013).

A partir desta perspectiva constatou-se que, atualmente, os trabalhadores enfrentam diversos problemas oriundos do mercado flexibilizado, tanto de ordem financeira, quanto as de ordem físicas e psicossomáticas, o que aponta para a existência da precarização do labor.

\section{Referências}

ANTUNES, Ricardo. O privilégio da servidão: o novo proletariado de serviços na era digital. São Paulo: Boitempo, 2018.

ANTUNES, Ricardo. Os sentidos do trabalho: ensaio sobre a afirmação e a negação do trabalho. São Paulo: Almedina, 2014. E-book.

ARAÚJO, Cléia Coutinho da Mota; FARIAS, Rafaela Cabral. O trabalho informacional e a precarização do novo trabalhador do setor de telemarketing em Imperatriz-MA. Temporalis, [S.1.], v. 15, n. 30, p. 205-226, jan. 2016. Disponível em: http://periodicos.ufes.br/temporalis/article/view/10985. Acesso em: 20 maio 2019.

ARAÚJO, Marcos Vinícius Ribeiro de. Adoecimento no trabalho: o discurso das teleoperadoras acerca dos distúrbios da voz. Distúrbios da Comunicação, [S.1.], v. 25, n. 1, abr. 2013. ISSN 2176-2724. Disponível em: https://revistas.pucsp.br/dic/article/ view/14928. Acesso em: 20 maio 2019.

BARRADAS, Liana França Dourado. Marx e a divisão do trabalho no capitalismo. São Paulo: Instituto Lukács, 2014.

BARRETO JUNIOR, José. Bancários eterceirizados no teleatendimento: funçóes iguais, realidades distintas. Dissertação [mestrado]. Pontifícia Universidade Católica, São Paulo, 2012.

BOTELHO, Adriano. Do fordismo à produção flexivel: a produção do espaço num contexto de mudança das estratégias da acumulação do capital. São Paulo: Annablume, 2008.

BRASIL. Decreto no 200, de 25 de fevereiro de 1967. Disponível em: http://www.planalto.gov.br/ccivil_03/decreto-lei/del0200.htm. Acesso em: 20 jan. 2019. 
BRASIL. Lei no 13.429, de 31 de março de 2017. Disponível em: http:/www.planalto.gov.br/ccivil_03/_ato2015-2018/2017/lei/L13429.htm. Acesso em: 25 fev. 2019.

BRASIL. Lei no 13.467, de 14 de julho de 2017. Disponível em: https://www.normaslegais.com.br/legislacao/Lei-13467-2017.htm. Acesso em: 12 jan. 2019.

BRASIL. Lei no 13.424, de 28 de março de 2017. Disponível em: http:/www.planalto.gov.br/ccivil_03/_Ato2015-2018/2017/Lei/L13424.htm. Acesso em: 15 jan. 2019.

BRASIL. Lei no 5.452, de 1 de maio de 1943. Disponível em: http://www.planalto.gov.br/ccivil_03/decreto-lei/del5452.htm. Acesso em: 23 jan. 2019.

BRASIL. Lei no 5.645, de 10 de dezembro de 1970. Disponível em: http:/www.planalto.gov.br/ccivil_03/LEIS/L5645.htm. Acesso em: 20 jan. 2019.

BRASIL. Lei no 6.019, de 3 de janeiro de 1974. Disponível em: http://www.planalto.gov.br/ccivil_03/leis/L6019.htm. Acesso em: 10 jan. 2019.

BRASIL. Lei no 7.102, de 20 de junho de 1983. Disponível em: http://www.planalto.gov.br/ccivil_03/LEIS/L7102.htm. Acesso em: 17 jan. 2019.

BRASIL. Lei no 8.863, de 28 de março de 1994. Disponível em: http://www.planalto.gov.br/ccivil_03/LEIS/L8863.htm. Acesso em: 8 jan. 2019.

BRASIL. Lei no 8.949, de 9 de dezembro de 1994. Disponível em: http://www.planalto.gov.br/ccivil_03/LEIS/L8949.htm. Acesso em: 16 jan. 2019.

BRASIL. Tribunal Superior do Trabalho. Súmula n² 256. In: BRASIL. Súmulas. Brasília, 2003. Disponível em: http://www3.tst.jus.br/jurisprudencia/Sumulas_com_ indice/Sumulas_Ind_251_300.html\#SUM-256. Acesso em: 18 jan. 2019.

BRASIL. Tribunal Superior do Trabalho. Súmula nº 331. In: BRASIL. Súmulas. Brasília, 2011. Disponível em: http://www3.tst.jus.br/jurisprudencia/Sumulas_com_ indice/Sumulas_Ind_301_350.html\#SUM-331. Acesso em: 18 jan.2019.

BRITO FILHO, José Claudio Monteiro de. Direito sindical: análise do modelo brasileiro de relaçóes coletivas de trabalho à luz do direito estrangeiro comparado e da doutrina da OIT - Proposta da inserção da comissáo da empresa. Sáo Paulo: LTr, 2018.

BRITO FILHO, José Claudio Monteiro de. Trabalho decente: análise jurídica da exploração do trabalho: trabalho escravo e outras formas de trabalho indigno. São Paulo: LTr, 2013. 
CASTELLS, Manuel. A sociedade em rede. Tradução de Roneide Venancio Majer. São Paulo: Paz e Terra, 2005.

CASTILLO, Juan José. O trabalho do conhecimento na sociedade da informação: análise dos programadores de software. In: ANTUNES, R. e BRAGA, R. Infoproletários: degradação real do trabalho virtual. São Paulo: Boitempo, 2009.

CAVALCANTE, Sávio. Tendências da configuração do trabalho no setor de telecomunicações no Brasil. Lutas Sociais, São Paulo, n. 24, p. 44-59, 2010.

COUTINHO, Grijalbo Fernandes. Terceirização: máquina de moer gente trabalhadora - A inexorável relação entre a nova marchandage e a degradação laboral, as mortes e mutilaçóes no trabalho. São Paulo: LTr, 2015.

DELGADO, Maurício Godinho. Curso de Direito do Trabalho. São Paulo: LTr, 2015.

DIEESE, Departamento Intersindical de Estatística e Estudos Socioeconômicos. Terceirização e precarização das condiçôes de trabalho: Condições de trabalho e remuneração em atividades tipicamente terceirizadas e contratantes, no 172, 2017. Disponível em: https://www.dieese.org.br/notatecnica/2017/notaTec172Terceirizacao. pdf. Acesso em: 20 maio de 2019.

HARVEY, David. Condição pós-moderna. Tradução: Adail Ubirajara Sobra; Maria Stela Gonçalves. São Paulo: Edições Loyola, 1989.

HUWS, Úrsula. A construção de um cibertariado? Trabalho virtual num mundo real. In: ANTUNES, Ricardo; BRAGA, Ruy. Infoproletários: degradação real do trabalho virtual. São Paulo: Boitempo, 2015.

HUWS. Úrsula. O escritório global: Tecnologias da Informação e a realocação do trabalho de colarinho branco. Tradução de Antônio de Pádua Bosi e Alessandra Gasparotto. Nova York: Tempos Históricos, 2003.

IPEA - INSTITUTO DE PESQUISA ECONÔMICA APLICADA. Impactos da Terceirização sobre a remuneração do trabalho no Brasil: novas evidências para o debate. (Org.) CAMPOS. André Gambier. Brasília. IPEA 2016. Disponível em: http://www. ipea.gov.br/portal/index.php?option=com_content\&view=article\&id=28817. Acesso em: 5 set. 2018 .

IPEA - INSTITUTO DE PESQUISA ECONÔMICA APLICADA. Os Sindicatos no Brasil. CARDOSO, Adalberto. Brasília. IPEA 2014. Disponível em: http://repositorio. ipea.gov.br/handle/11058/3765. Acesso em: 4 abr. 2019.

KOURY, Suzy Elizabeth Cavalcante. A Terceirização e o incremento dos acidentes de trabalho: um estudo sobre o setor elétrico. In: MISAILIDIS, Mirta Gladys Lerena Manzo de; SILVA, Lucas Gonçalves da; BARBATO, Maria Rosaria (Org.). Direito do trabalho. Santa Catarina: Florianópolis, 2014. 
LARANJEIRA, Sonia. FORDISMO E PÓS-FORDISMO. In: CATTANI, Antonio David (Org.). Trabalho e Tecnologia. Petrópolis, Porto Alegre: 4. ed. Vozes, 2002.

MANNRICH, Nelson. Operadores de teleatendimento (telemarketing): algumas reflexóes. Revista do Tribunal do Trabalho da $1^{\circ}$ Regiáo, Rio de Janeiro, v.21, n.48, p. 69-79, 2010.

MARX, Karl. O Capital: Crítica da economia política. Livro I: O processo de produção do capital. Trad. Rubens Enderle. São Paulo: Boitempo, 2013. Disponível em: https:// coletivocontracorrente.files.wordpress.com/2013/10/tmpsq7jbv.pdf. Acesso em: 9 abr. 2018.

NASCIMENTO, Érica. Jovens (Org.). Sindicatos e trabalho no setor de telemarketing. 2007. Disponível em: http://bibjuventude.ibict.br/jspui/handle/192/163. Acesso em: 17 abr. 2019.

NETO, João Amato. Reestruturação Industrial, terceirização e redes de subcontratação. Revista de Administração de Empresas - RAE, São Paulo, v. 35, n. 2, p. 33-42, mar. 1995.

PINTO, Geraldo. A organização do trabalho no século XX: Taylorismo, Fordismo e Toyotismo. São Paulo: Expressão Popular, 2013.

POCHMANN. Marcio. A terceirização global. 2011. Disponível em: http://www. revistaforum.com.br/2011/10/21/a-terceirizacao-global/. Acesso em: 7 mar. 2018.

ROSSO, Sadi. $O$ ardil da flexibilidade: os trabalhadores e a teoria do valor. São Paulo: Boi Tempo, 2017.

SILVA, José Carlos da. A reestruturação produtiva no setor bancário em Santa Catarina. Revista de Ciências da Administração, Florianópolis, p. 89-100, jan. 2002. Disponível em: https://periodicos.ufsc.br/index.php/adm/article/view/1908. Acesso em: 20 maio 2019.

STEIN, Guilherme; ZYLBERSTAJN, Eduardo; ZYLBERSTAJN, Hélio. Diferencial de salários da mão de obra terceirizada no Brasil. Estudos Econômicos. São Paulo, v. 47, n. 3, p. 587-612, 2017.

TAKAHASHI, Luis Torahiko; FERNANDES, Dário Cecílio. Avaliação da vulnerabilidade ao estresse no trabalho de operadores de Telemarketing. Psicologia: Organização e Trabalho, São Paulo, n. 14, p. 336-346, 2014.

VENCO, Selma; BARRETO, Margarida. O sentido social do suicídio no trabalho. Espaço Acadêmico, n. 108, 2010. 